06

\title{
Влияние кислорода и паров воды на электрические свойства наногранулированных композитов $\left(\mathrm{Co}_{40} \mathrm{Fe}_{40} \mathrm{~B}_{20}\right)_{x}\left(\mathrm{LiNbO}_{3}\right)_{100-x}$
}

\author{
(C) А.В. Ситников, ${ }^{1,2}$ И.В. Бабкина, ${ }^{1}$ Ю.Е. Калинин, ${ }^{1}$ А.Е. Никонов, ${ }^{1}$ М.Н. Копытин, ${ }^{1,}$ ฯ А.P. Шакуров, ${ }^{1}$ \\ B.В. Рыльков ${ }^{2}$ \\ ${ }^{1}$ Воронежский государственный технический университет, \\ 394006 Воронеж, Россия \\ ${ }^{2}$ Национальный исследовательский центр „Курчатовский институт“, \\ 123182 Москва, Россия \\ ฯ e-mail: michaelkopitin@mail.ru
}

Поступило в Редакцию 26 марта 2021 г.

В окончательной редакции 21 апреля 2021 г.

Принято к публикации 22 апреля 2021 г.

\begin{abstract}
Исследовано влияние кислорода и паров воды в распылительной камере в процессе осаждения тонкопленочных нанокомпозитов $\left(\mathrm{Co}_{40} \mathrm{Fe}_{40} \mathrm{~B}_{20}\right)_{x}\left(\mathrm{LiNbO}_{3}\right)_{100-x}$ на электрические свойства гетерогенной системы. Установлено существенное увеличение удельного электрического сопротивления нанокомпозитов $\left(\mathrm{Co}_{40} \mathrm{Fe}_{40} \mathrm{~B}_{20}\right)_{x}\left(\mathrm{LiNbO}_{3}\right)_{100-x}$ с увеличением парциального давления реактивных газов: кислорода и паров воды. Обнаружен существенный сдвиг порога протекания в плоскости и перпендикулярно пленке при синтезе композитов с добавлением реактивных газов в сторону больших значений металлической фазы, что связывается с увеличением объемной концентрации диэлектрической фазы. Выявлено, что порог протекания при измерении в перпендикулярной к плоскости пленки геометрии имеет существенно меньшую концентрацию атомов сплава $\mathrm{Co}_{40} \mathrm{Fe}_{40} \mathrm{~B}_{20}$, чем в случае измерений в плоскости пленки, что связано с вытянутой формой гранул в направлении роста пленки и эффектами подавления кулоновской блокады сильным поперечным электрическим полем.
\end{abstract}

Ключевые слова: электрическое сопротивление, порог протекания, анизотропия, кислород, пары воды.

DOI: 10.21883/JTF.2021.09.51219.84-21

\section{Введение}

Наногранулированные композиты металл-диэлектрик продолжают оставаться объектом научных интересов исследователей, что связано с наличием в них многих интересных для практического применения физических свойств [1-3]. Изменяя концентрацию магнитной и диэлектрической фаз, можно в широких пределах изменять электрические, магнитные, магниторезистивные и другие свойства гетерогенных систем [4,5]. Большое влияние на физические свойства гранулированных композитов оказывают условия их синтеза, в частности, наличие в распылительной камере реактивных газов [6]. В последние годы нанокомпозиты предложено использовать в качестве функциональной среды при разработке мемристивных элементов, предназначенной для создания многоуровневой памяти и других устройств, в которых используется эффект резистивного переключения из одного состояния (высокоомного) в другое (низкоомное) и наоборот [7-9]. Ключевую роль в процессе такого переключения играют кислородные вакансии $[10,11]$, поэтому введение кислорода в распылительную камеру должно оказывать влияние и на физические свойства синтезированных композитов. Понимание влияния параметров синтеза на физические свойства наноструктурированных гетерогенных пленок позволит управлять критическими функциональными свойствами последних для достижения оптимальных параметров мемристивных элементов.

Электрические свойства композитов наиболее чувствительны к присутствию в рабочей атмосфере активных газов при ионно-плазменном напылении пленок. Так, несколько парциальных процентов кислорода или азота, добавленные в атмосферу аргона при синтезе композита $\left(\mathrm{Co}_{40} \mathrm{Fe}_{40} \mathrm{~B}_{20}\right)_{x}\left(\mathrm{SiO}_{2}\right)_{100-x}$, значительно изменяют положение порога протекания последнего [12]. Основным остаточным газом в вакуумной камере при безмасляной системе откачки являются пары воды. Исследование влияния паров воды на электрические свойства композитов, в частности $\left(\mathrm{Co}_{40} \mathrm{Fe}_{40} \mathrm{~B}_{20}\right)_{x}\left(\mathrm{LiNbO}_{3}\right)_{100-x}$, не проводилось, хотя к элементам, входящим в состав данной гетероструктуры, он может быть весьма активен.

С учетом вышесказанного, задачей настоящей работы являлось установление основных закономерностей влияния добавления кислорода и паров воды на электрические свойства композита $\left(\mathrm{Co}_{40} \mathrm{Fe}_{40} \mathrm{~B}_{20}\right)_{x}\left(\mathrm{LiNbO}_{3}\right)_{100-x}$.

\section{1. Методика эксперимента}

Пленки нанокомпозита $\left(\mathrm{Co}_{40} \mathrm{Fe}_{40} \mathrm{~B}_{20}\right)_{x}\left(\mathrm{LiNbO}_{3}\right)_{100-x}$ были получены методом ионно-лучевого распыления [13]. Мишень состояла из металлического основания сплава $\mathrm{Co}_{40} \mathrm{Fe}_{40} \mathrm{~B}_{20}$ размером $270 \times 80 \times 15 \mathrm{~mm}$, на 
поверхности которой неравномерно по длине мишени были закреплены 15 полосок монокристаллического соединения $\mathrm{LiNbO}_{3}$ размером $80 \times 10 \times 2 \mathrm{~mm}$. Четыре ситалловые подложки располагались в ряд вдоль оси мишени, создавая площадь нанесения $240 \times 48 \mathrm{~mm}$. Расстояние между мишенью и камерой составляло около $120 \mathrm{~mm}$. Такая компоновка составной мишени и подложек позволяла в одном технологическом цикле получать образцы с различным соотношением диэлектрической и металлической фазы в зависимости от взаимного расположения системы мишень-подложка. Толщина пленки составляла $\sim 0.4 \mu \mathrm{m}$. Были синтезированы два вида образцов:

- металл (контакты)/композит - для измерения электрической проводимости вдоль поверхности пленки;

- металл (контакты)/композит/металл - для измерения электрической проводимости в перпендикулярной к поверхности геометрии.

Концентрация активных газов по отношению к аргону изменялась от 0.05 до $2.2 \%$ для кислорода и от 0.03 до $3.2 \%$ для паров воды. Металлическая фаза в одном цикле напыления изменялась от 10 до 40 at.\%. Состав остаточных газов в вакуумной камере измерялся квадрупольным масс-спектрометром Extorr XT-100.

Электрическое сопротивление измерялось на зондовой станции источником-измерителем напряжения и силы тока Keithley 2450.

Изображения высокого разрешения, полученные методом просвечивающей электронной микроскопии и просвечивающей растровой электронной микроскопии, картины дифракции электронов от выделенной области и микроанализ были зарегистрированы с помощью просвечивающего/растрового электронного микроскопа (П/РЭМ) Tecnai Osiris (Thermo Fisher Scientific, CША) при ускоряющем напряжении $200 \mathrm{keV}$, снабженного энергодисперсионным рентгеновским спектрометром Super-X (Bruker, США) и высокоугловым кольцевым темнопольным детектором (Fischione, США).

\section{2. Результаты исследований}

\section{1. Структура пленок}

Для аттестации синтезированных пленок были проведены исследования пленок методом просвечивающей электронной микроскопии (рис. 1). Анализ полученных результатов показал, что металлические гранулы имеют вытянутую форму в направлении роста пленки. В плоскости пленки омические контакты располагались на расстоянии $\sim 150 \mu \mathrm{m}$, а в перпендикулярном направлении на расстоянии $0.4 \mu \mathrm{m}$ (толщина пленки). Вытянутая форма гранул предполагает соответствующую анизотропию формы кластеров соприкасающихся проводящих гранул. Перколяционный кластер соприкасающихся металлических гранул начинает формироваться до достижения концентрации $x_{c}$, соответствующей порогу протекания композита. С увеличением концентрации металлической фазы размер перколяционного кластера увеличивается и, когда он сравнивается с расстоянием между контактами, с которых осуществляется измерение электрических характеристик, мы фиксируем положение порога протекания. Надо отметить, что распределение атомов $\mathrm{Fe}$ (рис. $1, c)$ более изотропно, чем атомов Со (рис. $1, d)$, следовательно, количество первых в диэлектрической фазе превалирует над количеством вторых.

\section{2. Электрические свойства синтезированных пленок}

Наличие вытянутой формы металлических гранул в направлении, перпендикулярном подложке, указывает на возможность анизотропии электрических свойств композита. Поэтому измерения удельного электрического сопротивления нанокомпозитов $\left(\mathrm{Co}_{40} \mathrm{Fe}_{40} \mathrm{~B}_{20}\right)_{x}\left(\mathrm{LiNbO}_{3}\right)_{100-x}$ с добавлением $\mathrm{O}_{2}$ и паров $\mathrm{H}_{2} \mathrm{O}$ были проведены в двух различных геометрических направлениях: вдоль и перпендикулярно поверхности пленки. Анализ концентрационных зависимостей удельного электрического сопротивления $(\rho(x))$ в плоскости пленки для нанокомпозитов $\left(\mathrm{Co}_{40} \mathrm{Fe}_{40} \mathrm{~B}_{20}\right)_{x}\left(\mathrm{LiNbO}_{3}\right)_{100-x}$, полученных с добавлением кислорода, показал, что значения $\rho(x)$ существенно увеличиваются с ростом концентрации $\mathrm{O}_{2}$ в области исследуемых составов (рис. 2,a). Это связано с доокислением соединения $\mathrm{LiNbO}_{3}$ и частичным окислением компонентов сплава $\mathrm{Co}_{40} \mathrm{Fe}_{40} \mathrm{~B}_{20}$. Концентрация металлической фазы, которая соответствует порогу протекания в случае планарных измерений, была определена по точке пересечения концентрационных зависимостей удельного электрического сопротивления образцов в исходном состоянии и подвергнутых термической обработке в вакууме при температуре, не приводящей к структурным изменениям нанокомпозита $\left(300^{\circ} \mathrm{C}, 30 \mathrm{~min}\right)$ (вставка рис. 2) [4]. Используемый метод определения порога протекания обоснован тем, что термообработка композитов, находящихся до порога протекания, приводит к росту электрического сопротивления, а для композитов за порогом протекания - к его уменьшению.

Аналогичные измерения удельного электрического сопротивления вдоль поверхности пленки были измерены для нанокомпозитов $\left(\mathrm{Co}_{40} \mathrm{Fe}_{40} \mathrm{~B}_{20}\right)_{x}\left(\mathrm{LiNbO}_{3}\right)_{100-x}$ при добавлении в распылительную камеру паров $\mathrm{H}_{2} \mathrm{O}$ (рис. 2,b). Анализ полученных зависимостей показал подобные для кислорода закономерности: значения $\rho(x)$ также увеличиваются с ростом концентрации паров воды. При этом степень увеличения удельного электрического сопротивления композита $\left(\mathrm{Co}_{40} \mathrm{Fe}_{40} \mathrm{~B}_{20}\right)_{x}\left(\mathrm{LiNbO}_{3}\right)_{100-x}$ в случае добавления одинаковых парциальных количеств реактивных газов больше для $\mathrm{O}_{2}$, чем для паров $\mathrm{H}_{2} \mathrm{O}$.

Концентрационные зависимости удельного электрического сопротивления нанокомпозитов $\left(\mathrm{Co}_{40} \mathrm{Fe}_{40} \mathrm{~B}_{20}\right)_{x}\left(\mathrm{LiNbO}_{3}\right)_{100-x}$ перпендикулярно плоскос- 

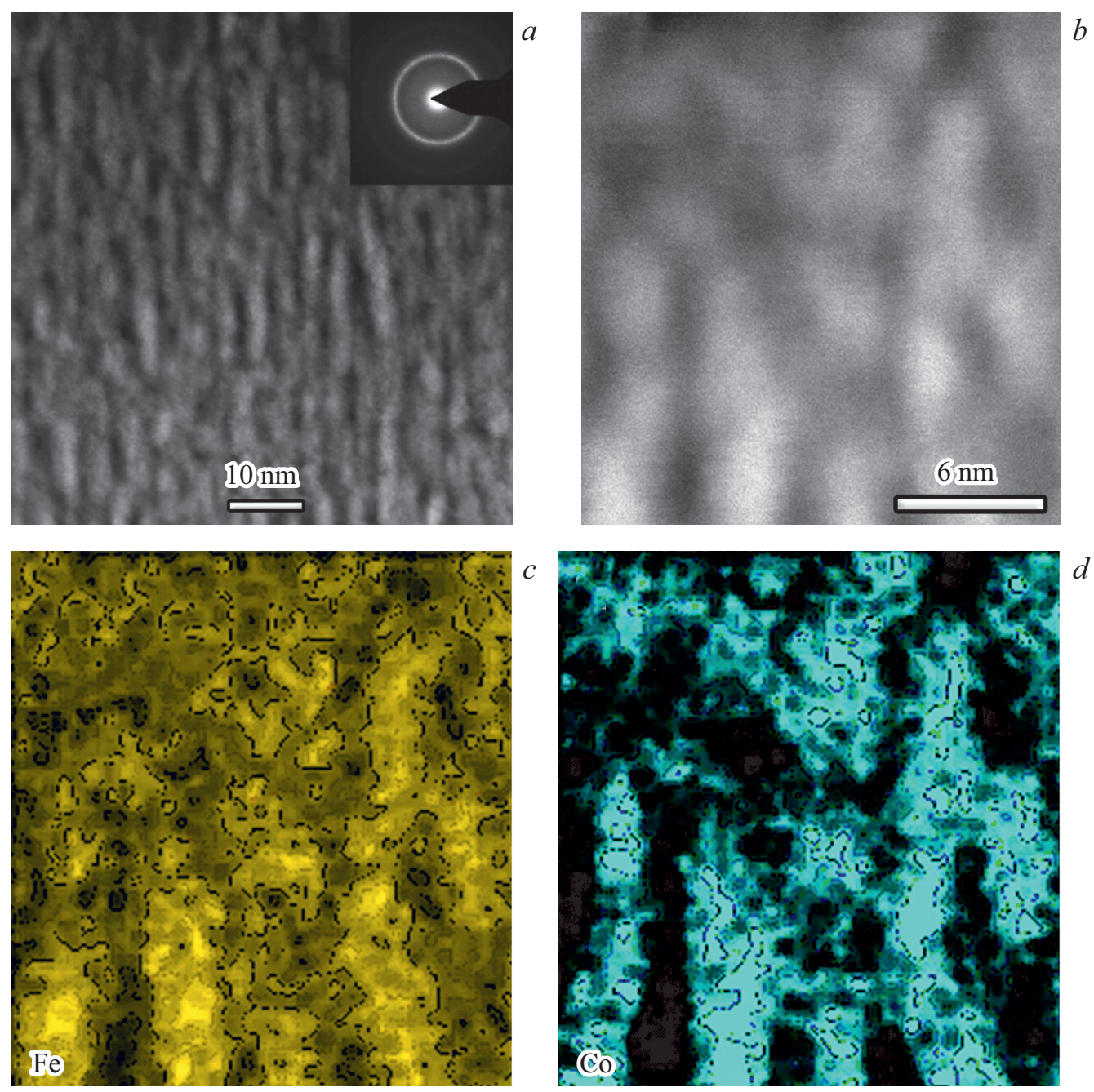

Рис. 1. $a, b-\mathrm{HAADF}$ STEM-изображение поперечного сечения пленки композита $\left(\mathrm{Co}_{40} \mathrm{Fe}_{40} \mathrm{~B}_{20}\right)_{x}\left(\mathrm{LiNbO}_{3}\right)_{100-x}(x=48$ at.\%), полученного при парциальном давлении кислорода $1.4 \%$, и элементные карты $\mathrm{Fe}(c)$ и Со $(d)$.

ти пленки, полученные при различных парциальных давлениях кислорода, представлены на рис. 3, а. Измерения удельного электрического сопротивления в перпендикулярной к плоскости пленки геометрии показали, что и в этом случае значения $\rho(x)$ существенно увеличиваются с ростом концентрации $\mathrm{O}_{2}$. Концентрация металлической фазы, которая соответствует порогу протекания в случае перпендикулярной к плоскости пленки геометрии измерения электрического сопротивления, была определена по вырождению вольт-амперных характеристик $(\mathrm{BAX})$ образцов в линейную, безгистерезисную зависимость (вставка к рис. 3, $a$ ).

Аналогичные измерения удельного электрического сопротивления в направлении перпендикулярном поверхности пленки были выполнены для нанокомпозитов $\left(\mathrm{Co}_{40} \mathrm{Fe}_{40} \mathrm{~B}_{20}\right)_{x}\left(\mathrm{LiNbO}_{3}\right)_{100-x}$ при добавлении в распылительную камеру паров $\mathrm{H}_{2} \mathrm{O}$ (рис. 3 , b). Анализ полученных зависимостей и в этом случае показал закономерности подобные тем, что наблюдались при добавлении кислорода: значения $\rho(x)$ увеличиваются с ростом концентрации паров воды. При этом следует заметить, что степень увеличения удельного электрического сопротивления композитов $\left(\mathrm{Co}_{40} \mathrm{Fe}_{40} \mathrm{~B}_{20}\right)_{x}\left(\mathrm{LiNbO}_{3}\right)_{100-x}$ в случае добавления одинаковых парциальных количеств реактивных газов больше для $\mathrm{O}_{2}$, чем для паров $\mathrm{H}_{2} \mathrm{O}$.

Наиболее структурно чувствительным параметром в композиционных материалах является порог протекания, положение которого для нанокомпозитов $\left(\mathrm{Co}_{40} \mathrm{Fe}_{40} \mathrm{~B}_{20}\right)_{x}\left(\mathrm{LiNbO}_{3}\right)_{100-x}$ зависит от парциального давления реактивных газов и геометрии измерения электрического сопротивления, что представлено на рис. 4. Из анализа концентрационного положения порога протекания в нанокомпозитах $\left(\mathrm{Co}_{40} \mathrm{Fe}_{40} \mathrm{~B}_{20}\right)_{X}\left(\mathrm{LiNbO}_{3}\right)_{100-X}$ можно сделать следующие выводы:

1) положения порога протекания при пропускании тока в плоскости пленки и перпендикулярно ей отличаются почти в три раза: в перпендикулярной геометрии он соответствует меньшей концентрации $x$ металлического сплава $\mathrm{Co}_{40} \mathrm{Fe}_{40} \mathrm{~B}_{20}$, чем в случае измерений в плоскости пленки; 


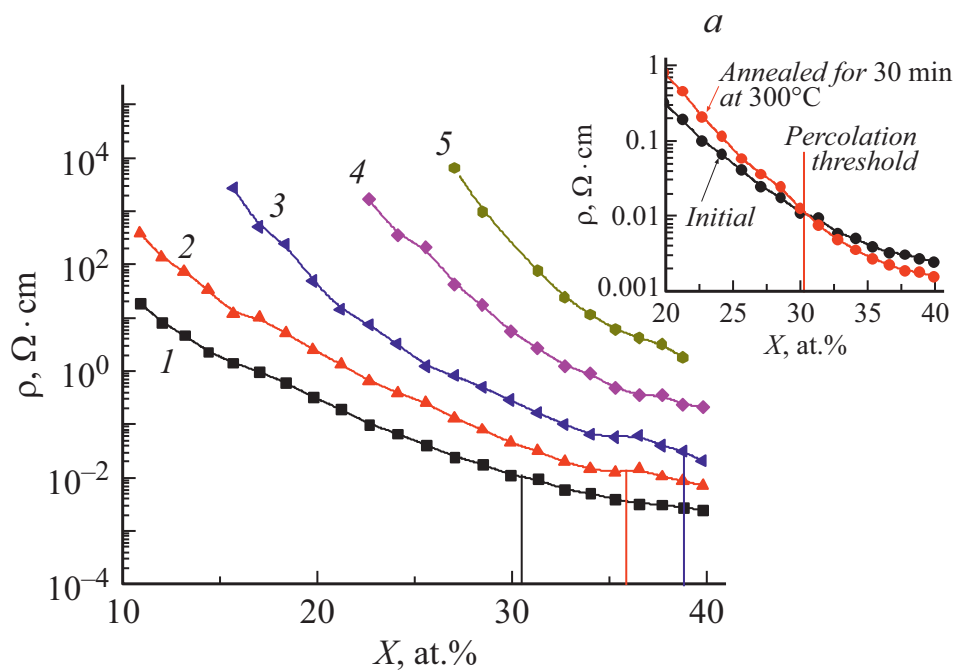

$b$

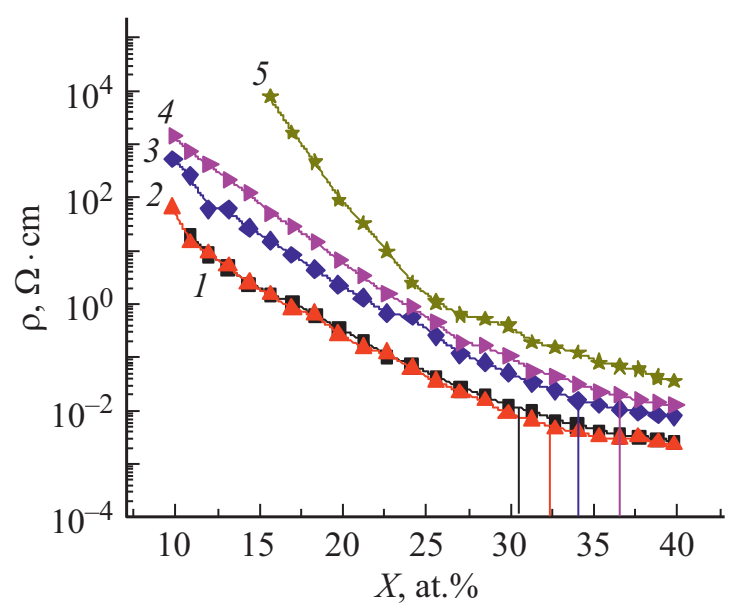

Рис. 2. Концентрационные зависимости удельного электрического сопротивления нанокомпозитов $\left(\mathrm{Co}_{40} \mathrm{Fe}_{40} \mathrm{~B}_{20}\right)_{x}\left(\mathrm{LiNbO}_{3}\right)_{100-x}$ в плоскости пленки, полученных при различных парциальных давлениях кислорода: $1-0.05,2-1.0,3-1.4,4-1.8$, $5-2.2 \%(a)$ и $\mathrm{H}_{2} \mathrm{O}: 1-0.3,2-0.6,3-1.0,4-2.0,5-3.2 \%(b)$. Вертикальные линии показывают концентрацию металлической фазы, соответствующую порогу протекания. Вставка: концентрационные зависимости удельного электрического сопротивления нанокомпозита $\left(\mathrm{Co}_{40} \mathrm{Fe}_{40} \mathrm{~B}_{20}\right)_{x}\left(\mathrm{LiNbO}_{3}\right)_{100-x}$ при парциальном давлении кислорода 0.05\% в исходном состоянии и после термической обработки.
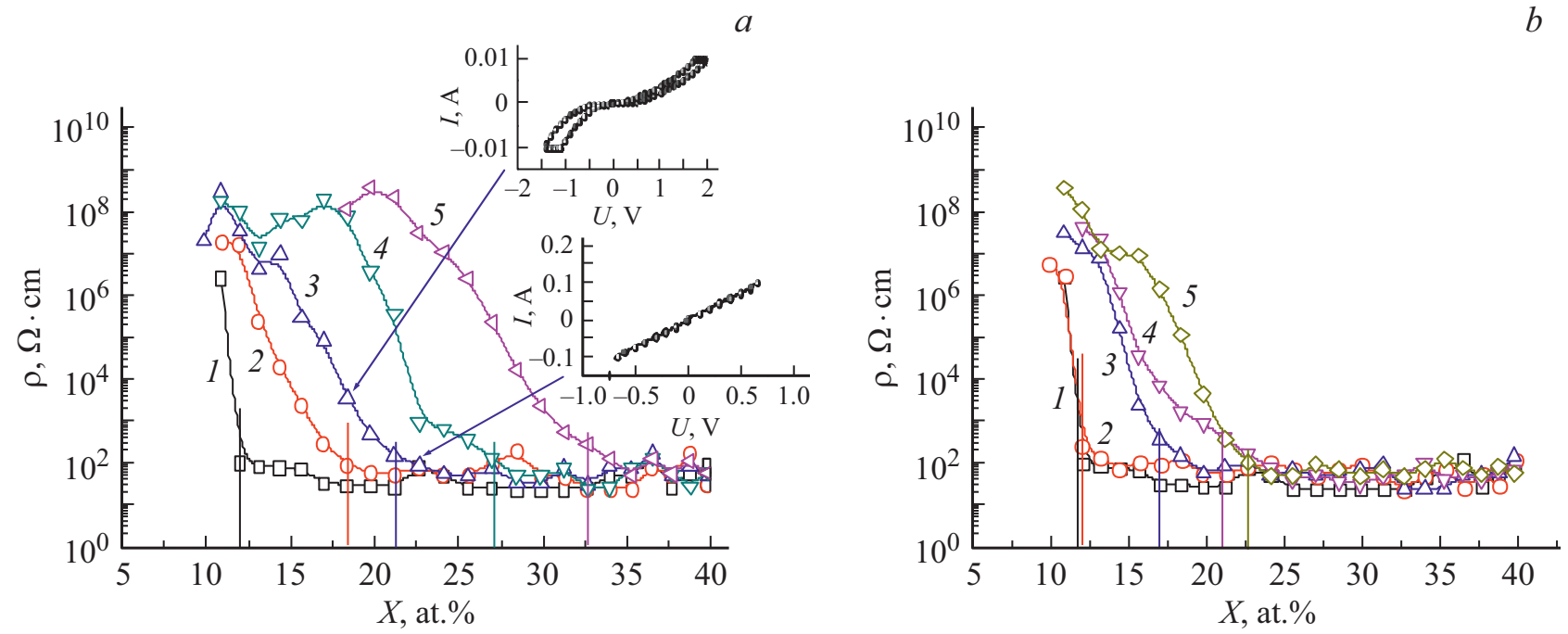

Рис. 3. Концентрационные зависимости удельного электрического сопротивления нанокомпозитов $\left(\mathrm{Co}_{40} \mathrm{Fe}_{40} \mathrm{~B}_{20}\right)_{x}\left(\mathrm{LiNbO}_{3}\right)_{100-x}$ перпендикулярно плоскости пленки, полученных при различных парциальных давлениях кислорода: $1-0.05,2-1.0$, 3 - 1.4, $4-1.8,5-2.2 \%(a)$ и паров $\mathrm{H}_{2} \mathrm{O}: 1-0.3,2-0.6,3-1.0,4-2.0,5-3.2 \%$ (b). Вертикальные линии показывают концентрацию металлической фазы, соответствующую порогу протекания. Вставка: ВАХ нанокомпозита $\left(\mathrm{Co}_{40} \mathrm{Fe}_{40} \mathrm{~B}_{20}\right)_{x}\left(\mathrm{LiNbO}_{3}\right)_{100-x}$ при парциальном давлении кислорода $0.05 \%$ в исходном состоянии и после термической обработки.

2) при добавлении молекул кислорода и паров воды положение порога протекания сдвигается в область с большим значением концентрации $x$ металлической фазы;

3) молекулы кислорода оказывают более существенное влияние на смещение положения порога протекания в область больших значений $x$ по сравнению с парами воды.

\section{3. Обсуждение полученных результатов}

Для описания переноса заряда в нанокомпозитах с различными концентрациями и формами гранул применяют теорию протекания, в которой рассматривают решеточные задачи узлов и задачи связей [14]. В обоих случаях одной из задач теории протекания является 


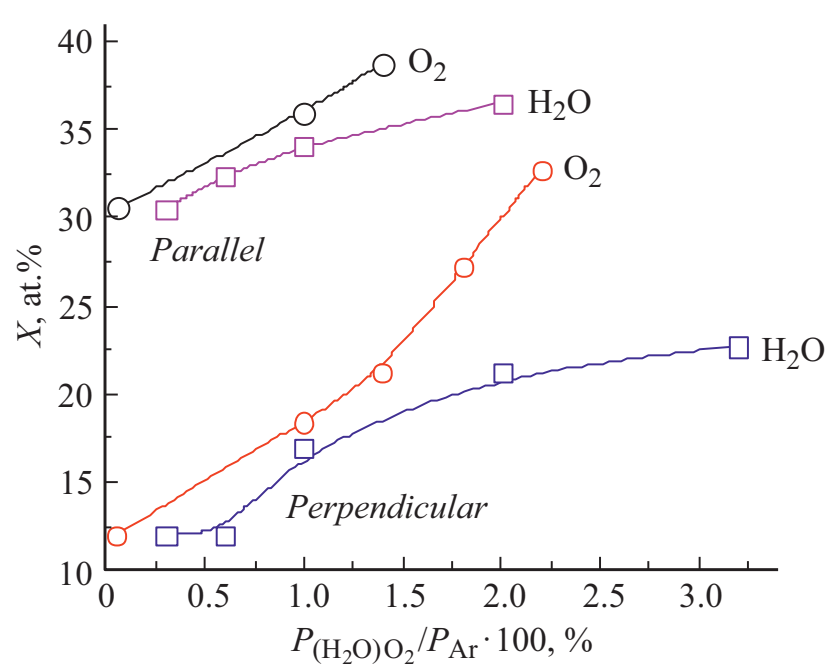

Pис. 4. Зависимости положения порога протекания нанокомпозита $\left(\mathrm{Co}_{40} \mathrm{Fe}_{40} \mathrm{~B}_{20}\right)_{x}\left(\mathrm{LiNbO}_{3}\right)_{100-x}$ от парциального давления реактивных газов и геометрии измерения электрического сопротивления.

определение так называемого порога протекания - критической концентрации $x_{c}$, при которой применительно к электрической проводимости ее эффективная величина отличается от нуля. Для композитов металл-диэлектрик со сферической формой металлических гранул, хаотично распределенных в диэлектрической матрице, независимо от условий измерения электрического сопротивления (вдоль или перпендикулярно направлению прессования композитов), система оказывается изотропной и экспериментально можно зафиксировать только один порог протекания [15]. В случае саже- и графитонаполненных композитов порог протекания соответствует $x_{c} \sim 0.2$ и 0.3 , а для металлонаполненных композитов он сдвинут в область $x_{c}=0.5-0.6$ [16].

В работе [17] теория протекания применяется для описания анизотропии электропроводности композитов, в которых частицы наполнителя анизотропны. Макроскопическая электропроводность композита может быть анизотропной в двух случаях, когда:

- существует преимущественная ориентация частиц наполнителя, имеющих изотропную электропроводность и вытянутую форму;

- существует преимущественная ориентация частиц наполнителя, имеющих сферическую форму и анизотропную электропроводность.

В рамках теории протекания исследовались различные решеточные модели. При этом рассматривалось два варианта:

a) связи с различной ориентацией имеют одинаковое электрическое сопротивление, но различную вероятность образования связей $P$. В этом случае электропроводность связана с порогом протекания $p_{c}$, как

$$
\sigma(p)=\sigma_{m}\left(p-p_{c}\right)^{t}
$$

где $\sigma_{m}-$ проводимость материала при $x=1, t-$ критический индекс, $p$ - вероятность образования связей;

б) все связи имеют одинаковую вероятность $p$, но их электропроводность зависит от направления связи. Тогда проводимость системы анизотропна для всех значений $p$, но ее величина зависит от направления связи. В этом случае вводится коэффициент анизотропии $\sigma_{\|} / \sigma_{\perp}$ :

$$
\sigma_{\|} / \sigma_{\perp}-1 \propto\left(p-p_{c}\right)^{\lambda}
$$

где $\sigma_{\|}$и $\sigma_{\perp}-$ макроскопические электропроводности вдоль осей $z$ и $x, \lambda$ - новый критический индекс.

Композит с анизотропными сферами можно моделировать с помощью решеточной задачи (б), а композит с изотропными вытянутыми частицами - задачей связей (a). Коэффициент анизотропии композитов с анизотропными сферами падает с ростом содержания наполнителя следующим образом:

$$
\left(\sigma_{\|} / \sigma_{\perp}\right)-1 \propto\left(V_{f}-V_{f}^{*}\right)^{\lambda},
$$

где $V_{f}$ - концентрация наполнителя, $V_{f}^{*}-$ концентрация наполнителя, при которой возникает порог протекания.

Коэффициент анизотропии электропроводности композитов с вытянутыми изотропными включениями (типа эллипсоидов) на пороге протекания равен

$$
\left(\sigma_{\|} / \sigma_{\perp}\right)=(l / d)^{2}
$$

где $l$ - длина эллипсоида, $d$ - диаметр эллипсоида.

Выше порога протекания значение коэффициента анизотропии подчиняется следующему уравнению

$$
\left(\sigma_{\|} / \sigma_{\perp}\right)=(l / d)^{2}\left[1+A\left(V_{f}-V_{f}^{*}\right)^{\lambda}\right]
$$

где $A-$ константа.

В этом случае порог протекания композита при любом направлении измерения считался неизменным [16,18].

В исследуемых композитах наблюдается не только сильная анизотропия формы наполнителя в структуре синтезированных композитов, но и их преимущественная ориентация (рис. 1). При этом в пленочных нанокомпозиционных образцах наблюдается существенное различие в значениях $x_{c}$ для разной геометрии измерения проводимости: в планарной геометрии она приблизительно в 3 раза выше в сравнении с вертикальной геометрией измерения. Столь сильное различие в значениях $x_{c}$ для разной геометрии измерения проводимости ранее в наших работах $[13,19]$ объяснялось эффектами подавления кулоновской блокады электрическим полем $\left(\sim 10^{3} \mathrm{~V} / \mathrm{cm}[20]\right)$, а кроме того нуклеацией металлической фазы, сопровождаемой формированием цепочек из гранул, определяющих перколяционные пути электронного транспорта [7].

Существуют и другие варианты наблюдаемого различия в значениях $x_{c}$ для перпендикулярной и продольной геометрии расположения частиц наполнителя в 
$a$
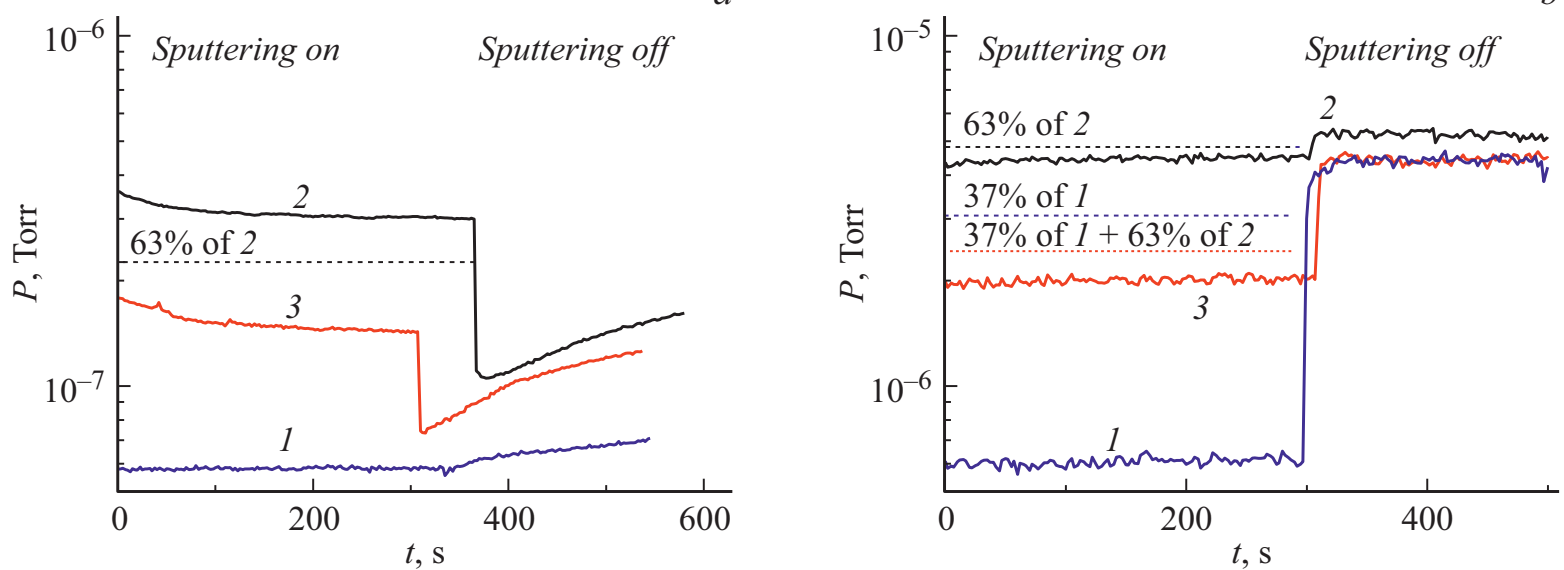

Рис. 5. Временные зависимости давления кислорода в вакуумной камере при распылении сплава $\mathrm{Co}_{40} \mathrm{Fe}_{40} \mathrm{~B}_{20}$ (кривая 1), соединения $\mathrm{LiNbO}_{3}$ (кривая 2) и составной мишени $\mathrm{Co}_{40} \mathrm{Fe}_{40} \mathrm{~B}_{20}$ с навесками из $\mathrm{LiNbO}_{3}$ (кривая 3) в атмосфере $\mathrm{Ar}(a)$ и в атмосфере $\mathrm{Ar}$ с добавлением $\mathrm{O}_{2}(2.2 \%)(b)$.

синтезированных пленках. На начальной стадии роста пленок в направлении, перпендикулярном плоскости пленки, наблюдается островковый рост металлических гранул, которые в пределе могут прорасти через всю толщину пленки, образовав композит, аналогичный композиту с волокнистым наполнителем, у которого порог протекания в этом направлении будет равен нулевому значению. В синтезированных в настоящей работе композитах металлическая фаза имеет конечные размеры, и формируемые структуры можно рассматривать как промежуточный вариант между композитом с волокнистым наполнителем, ориентированным перпендикулярно плоскости пленки, и композитом, в котором волокнистые наполнители имеют конечные размеры, ориентированы хаотично в матрице и не имеют непосредственного контакта. Синтезированные композиты имеют не только сильную анизотропию электропроводности вдоль и перпендикулярно плоскости пленки [16], но и различные значения $x_{c}$ при измерении в разных направлениях (рис. 4).

Значения $x_{c}$ в композитах, полученных в атмосфере аргона, отличаются примерно в 3 раза $\left(x_{c \|} \sim 30\right.$, а $x_{c \perp} \sim 11$ ат.\%), что коррелирует с отношением анизотропии формы металлических гранул $l / d$ (рис. 1 ). Введение кислорода в распылительную камеру в процессе синтеза композита приводит к увеличению значений порога протекания $x_{c \|}$ и $x_{c \perp}$, а также сближению этих величин, в то время как введение паров воды - только к их увеличению (рис. 4).

Наконец, на различие величин $x_{c \|}$ и $x_{c \perp}$ может оказывать рост перколяционного кластера, образуемого из соприкасающихся металлических гранул, который начинает формироваться еще до достижения концентрации, соответствующей порогу протекания композита. Поскольку в перпендикулярном направлении размер пленки существенно меньше, чем в продольном, то с увеличением концентрации металлической фазы перко- ляционный кластер в перпендикулярном направлении формируется раныше (когда его размер достигает расстояния между контактами), т.е. всегда выполняется соотношение $x_{c \perp}<x_{c \|}$. Все перечисленные факторы могут оказывать влияние на положение порога протекания и приводить к наблюдаемым экспериментальным результатам (рис. 4).

Для выявления возможных химических взаимодействий активных газов $\mathrm{c}$ элементами композита $\left(\mathrm{Co}_{40} \mathrm{Fe}_{40} \mathrm{~B}_{20}\right)_{x}\left(\mathrm{LiNbO}_{3}\right)_{100-x}$, влияющих на положение порога протекания, были проведены дополнительные исследования состава газовой среды в вакуумной камере в процессе синтеза пленки и после остановки процесса напыления. Комплексные измерения были проведены при распылении $\mathrm{Co}, \mathrm{Fe}$, сплава $\mathrm{Co}_{40} \mathrm{Fe}_{40} \mathrm{~B}_{20}$, соединения $\mathrm{LiNbO}_{3}$ и составной мишени $\mathrm{Co}_{40} \mathrm{Fe}_{40} \mathrm{~B}_{20}$ с навесками из $\mathrm{LiNbO}_{3}$ при различных парциальных давлениях $\mathrm{O}_{2}$ и паров $\mathrm{H}_{2} \mathrm{O}$.

Так, при распылении составной мишени $\mathrm{Co}_{40} \mathrm{Fe}_{40} \mathrm{~B}_{20} \mathrm{c}$ навесками $\mathrm{LiNbO}_{3}$ в атмосфере $\mathrm{Ar}$ было зафиксировано наличие избыточного давления $\mathrm{O}_{2}$, которое значительно убывает при выключении источников распыления (рис. 5, $a$, кривая 3). Аналогичное поведение газовой среды мы наблюдали при распылении мишени $\mathrm{LiNbO}_{3}$ (рис. 5, $a$, кривая 2), где данный эффект мы связываем с процессом удаления некоторой части распыленного кислорода из вакуумной камеры в процессе откачки. Результирующую реакцию осаждения можно представить, как $\mathrm{LiNbO}_{3}=\mathrm{LiNbO}_{n}+\mathrm{O}_{2}$, где $n<3$. С учетом того что в составной мишени навески $\mathrm{LiNbO}_{3}$ занимают 63\% поверхности (штриховая прямая линия на рис. 5,a) избыточное давление $\mathrm{O}_{2}$ остается меньше, чем при распылении керамики. Это можно объяснить тем, что часть выделенного кислорода входит в образующиеся окислы металлической фазы композита.

При добавлении кислорода в рабочий газ в вакуумной камере может происходить два процесса: доокисление 


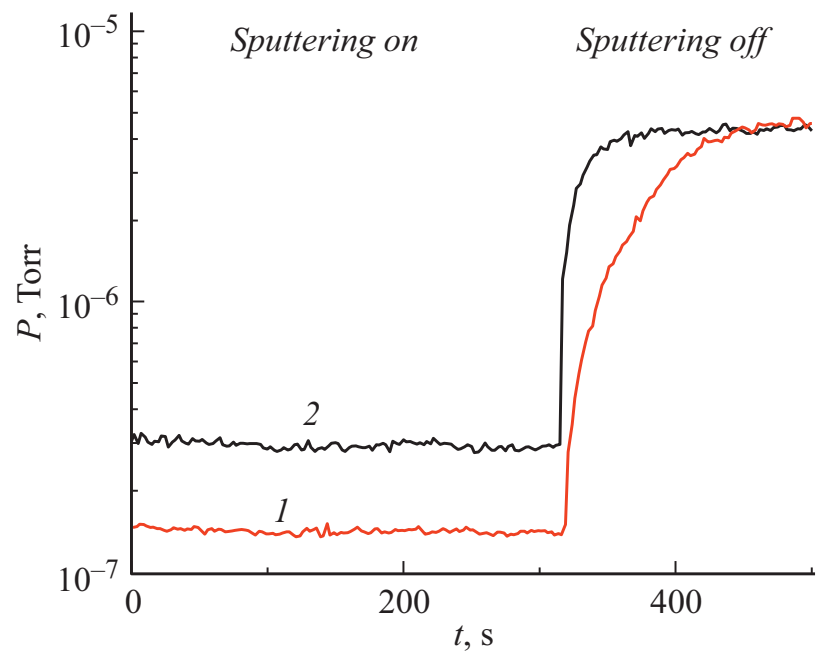

Рис. 6. Временные зависимости давления кислорода в вакуумной камере при распылении $\mathrm{Fe}$ (кривая 1) и Со (кривая 2) в атмосфере $\mathrm{Ar}$ с добавлением $\mathrm{O}_{2}(2.2 \%)$.

диэлектрической фазы $\left(\mathrm{LiNbO}_{3}\right)$ и окисление металлической фазы $\left(\mathrm{Co}_{40} \mathrm{Fe}_{40} \mathrm{~B}_{20}\right)$. Сравнение степени недостатка давления кислорода в вакуумной камере в процессе синтеза пленки $\left(\mathrm{Co}_{40} \mathrm{Fe}_{40} \mathrm{~B}_{20}\right)_{x}\left(\mathrm{LiNbO}_{3}\right)_{100-x}$, а также распыления соединения $\mathrm{LiNbO}_{3}$ и сплава $\mathrm{Co}_{40} \mathrm{Fe}_{40} \mathrm{~B}_{20}$ показывает, что основным механизмом связывания кислорода при распылении является окисление металлической фазы композита (рис. $5, b)$.

Однако процесс доокисления диэлектрической фазы также происходит, о чем свидетельствует увеличение содержания кислорода в камере в момент выключения источника распыления при осаждении пленки $\mathrm{LiNbO}_{3}$ (рис. $5, b$, кривая 2). Большая интенсивность поглощения $\mathrm{O}_{2}$ при распылении составной мишени в процессе синтеза композита относительно оценочных значений, которые учитывают соотношение площадей поверхности навесок $\mathrm{LiNbO}_{3}(\sim 63 \%)$ и сплава $\mathrm{Co}_{40} \mathrm{Fe}_{40} \mathrm{~B}_{20}(\sim 37 \%)$ в составной мишени (штриховые линии рис. $5, b$ ) может свидетельствовать о большей скорости реакции с кислородом на поверхности гетерогенной наноструктурированной пленки относительно гомогенных покрытий. При этом возможно протекание следующих реакций:

$$
\begin{aligned}
\mathrm{LiNbO}_{n}+\mathrm{O}_{2} & =\mathrm{LiNbO}_{3}, \\
2 \mathrm{Fe}+\mathrm{O}_{2} & =2 \mathrm{FeO}, \\
3 \mathrm{Fe}+2 \mathrm{O}_{2} & =\mathrm{Fe}_{3} \mathrm{O}_{4}, \\
2 \mathrm{Co}+\mathrm{O}_{2} & =2 \mathrm{CoO}, \\
4 \mathrm{Co}+3 \mathrm{O}_{2} & =2 \mathrm{Co}_{2} \mathrm{O}_{3} .
\end{aligned}
$$

Однако надо заметить, что скорость окисления кобальта значительно меньше, чем железа, что доказывает сравнительный анализ степени недостатка давления кислорода в вакуумной камере при процессе синтеза пленки $\mathrm{Co}$ и $\mathrm{Fe}$ (рис. 6). Эти доводы подтверждает динамика изменения концентрации $\mathrm{O}_{2}$ после остановки процесса синтеза металлов. В случае распыления Fе увеличение концентрации кислорода протекает значительно медленнее, что свидетельствует об интенсивном окислении железа на поверхности свеженапыленной пленки.

Несколько другие химические взаимодействия могут наблюдаться при формировании пленок композитов $\left(\mathrm{Co}_{40} \mathrm{Fe}_{40} \mathrm{~B}_{20}\right)_{x}\left(\mathrm{LiNbO}_{3}\right)_{100-x}$, если в рабочем газе присутствуют пары $\mathrm{H}_{2} \mathrm{O}$. Выделение $\mathrm{O}_{2}$ при осаждении композитов в среде $\left(\mathrm{Ar}+\mathrm{H}_{2} \mathrm{O}\right)$ (рис. 7, $a$, кривая 3) скорее всего имеет ту же причину, что и избыточное давление кислорода при распылении $\mathrm{LiNbO}_{3}$ в инертной (Ar) среде (рис. 5, $a$, кривая 2), о чем мы упоминали выше.

$b$

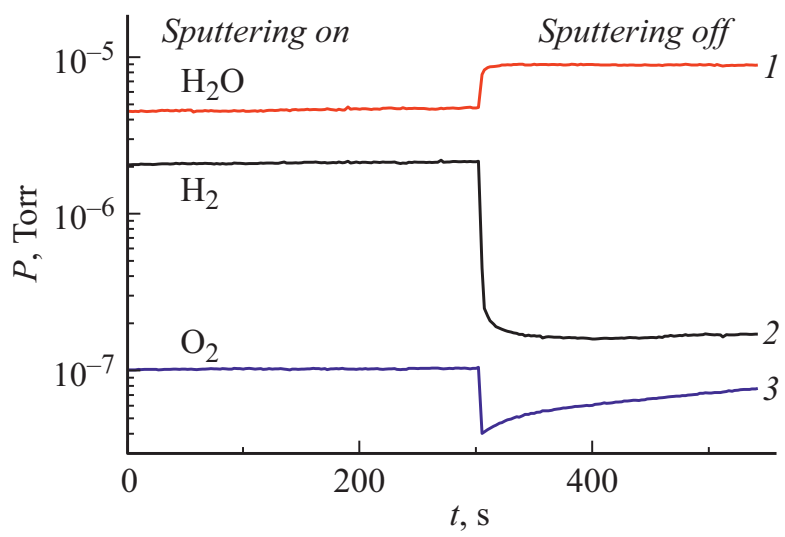

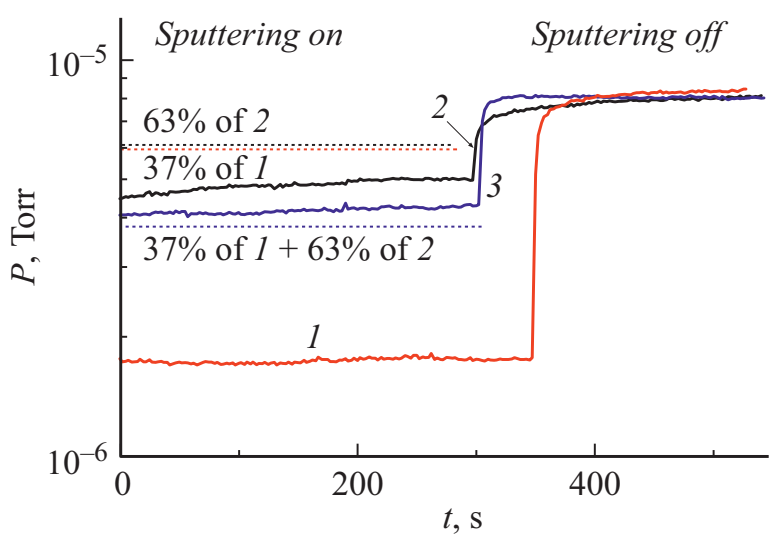

Рис. 7. Временные зависимости давления паров $\mathrm{H}_{2} \mathrm{O}$ (кривая 1), $\mathrm{H}_{2}$ (кривая 2) и $\mathrm{O}_{2}$ (кривая 3) в вакуумной камере при распылении составной мишени $\mathrm{Co}_{40} \mathrm{Fe}_{40} \mathrm{~B}_{20}$ с навесками из $\mathrm{LiNbO}_{3}$ в атмосфере $\mathrm{Ar}$ с добавлением паров $\mathrm{H}_{2} \mathrm{O}(3.2 \%)(a)$ и только паров $\mathrm{H}_{2} \mathrm{O}$ в вакуумной камере при распылении сплава $\mathrm{Co}_{40} \mathrm{Fe}_{40} \mathrm{~B}_{20}$ (кривая 1 ), соединения $\mathrm{LiNbO}_{3}$ (кривая 2) и составной мишени $\mathrm{Co}_{40} \mathrm{Fe}_{40} \mathrm{~B}_{20}$ с навесками из $\mathrm{LiNbO}_{3}$ (кривая 3) в атмосфере $\mathrm{Ar}$ с добавлением паров $\mathrm{H}_{2} \mathrm{O}(3.2 \%)$ (b). 
Сравнение энтальпии образования и энергии разрыва связей соединений $\mathrm{Li}$ и $\mathrm{Nb}$ [21]

\begin{tabular}{|c|c|c|c|c|c|}
\hline Соединение & $\begin{array}{c}\text { Энтальпия } \\
\text { образования, } \\
\Delta H_{f 0}, \mathrm{kcal} / \mathrm{mol}\end{array}$ & $\begin{array}{c}\text { Энергия } \\
\text { разрыва связи, } \\
\Delta H_{0}, \mathrm{kcal} / \mathrm{mol}\end{array}$ & Соединение & $\begin{array}{c}\text { Энтальпия } \\
\text { образования, } \\
\Delta H_{f 0}, \mathrm{kcal} / \mathrm{mol}\end{array}$ & $\begin{array}{c}\text { Энергия } \\
\text { разрыва связи, } \\
\Delta H_{0}, \mathrm{kcal} / \mathrm{mol}\end{array}$ \\
\hline $\begin{array}{c}\mathrm{LiO} \\
\mathrm{Li}_{2} \mathrm{O} \\
\mathrm{LiOH} \\
\mathrm{Li}_{2} \mathrm{O}_{2} \mathrm{H}_{2} \\
\mathrm{LiH} \\
\mathrm{LiH}_{2}\end{array}$ & $\begin{array}{c}16 \pm 3 \\
-40 \pm 2 \\
-58.1 \\
-185.4 \\
33.3 \pm 0.2 \\
24.2\end{array}$ & $\begin{aligned} & 81 \pm 3 \\
& 93 \pm 4 \\
& 105 \pm 4 \\
& 56 \pm 3 \\
& 56.015 \pm 0.005 \\
& 13.5\end{aligned}$ & $\begin{array}{c}\mathrm{NbO} \\
\mathrm{NbO}_{2}\end{array}$ & $\begin{aligned} & 50 \pm 10 \\
&-50 \pm 5 \\
&- \\
&-- \\
&-\end{aligned}$ & $\begin{array}{c}180 \pm 10 \\
160 \pm 10 \\
- \\
- \\
- \\
-\end{array}$ \\
\hline
\end{tabular}

Пары воды выступают как реагент. Их концентрация почти на порядок выше, чем в случае распыления в инертной атмосфере. Сравнение степени недостатка давления паров воды в вакуумной камере при синтезе композитов $\left(\mathrm{Co}_{40} \mathrm{Fe}_{40} \mathrm{~B}_{20}\right)_{x}\left(\mathrm{LiNbO}_{3}\right)_{100-x}$, а также распыления соединения $\mathrm{LiNbO}_{3}$ и сплава $\mathrm{Co}_{40} \mathrm{Fe}_{40} \mathrm{~B}_{20}$ с учетом их площадей поверхности в составной мишени $(63 \%$ $\mathrm{LiNbO}_{3}$ и $37 \%-\mathrm{Co}_{40} \mathrm{Fe}_{40} \mathrm{~B}_{20}$ ) (штриховые линии на рис. $7, b)$ показывает, что в пределах погрешности эксперимента скорость взаимодействия композита с парами воды совпадает с суммарными скоростями реакции фаз, входящих в состав гетерогенной системы.

Как правило, соединение $\mathrm{LiNbO}_{3}$ является стабильным и не реагирует с парами воды. По этой причине надо рассмотреть физические процессы, связанные с ионно-плазменным распылением данного оксида. При бомбардировке мишени ионами аргона с ее поверхности могут быть выбиты отдельные элементы в атомарном состоянии $(\mathrm{Li}, \mathrm{Nb}$ и $\mathrm{O})$ и в виде соединений различного молекулярного состава ( $\mathrm{LiO}, \mathrm{NbO}, \mathrm{LiNbO}$ и т.п.). Beроятность относительной концентрации данных простых и сложных продуктов распыления зависит от энергии связей между атомами. Исходя из этого, атомов $\mathrm{Li} \mathrm{в}$ потоке распыляемого соединения $\mathrm{LiNbO}_{3}$ должно быть больше, чем $\mathrm{Nb}$ по причине различных энергий разрыва связей $\mathrm{LiO}$ и $\mathrm{NbO}$ (см. таблицу). В результате поверхностной диффузии продуктов распыления происходит не только процесс самоорганизации наноструктурирированной гетерогенной системы $\left(\mathrm{Co}_{40} \mathrm{Fe}_{40} \mathrm{~B}_{20}\right)_{x}\left(\mathrm{LiNbO}_{3}\right)_{100-x}$, но и химические реакции на ее поверхности при столкновении активных атомов и молекул. Вероятность химических реакций зависит от энтальпии образования данного соединения и энергии разрыва связи продукта реакции. С этой точки зрения окисление $\mathrm{Nb}$ более вероятно, чем окисление $\mathrm{Li}$. В то же время $\mathrm{Li}$ более склонен образовывать соединения с молекулами $\mathrm{H}_{2} \mathrm{O}$ и ОН (см. таблицу).

Учитывая состав продуктов распыления, при синтезе композитов можно предположить протекание следующих реакций с парами $\mathrm{H}_{2} \mathrm{O}$ :

$$
\begin{gathered}
3 \mathrm{Fe}+4 \mathrm{H}_{2} \mathrm{O}=\mathrm{Fe}_{3} \mathrm{O}_{4}+4 \mathrm{H}_{2}, \\
\mathrm{Li}_{2} \mathrm{O}+\mathrm{H}_{2} \mathrm{O}=2 \mathrm{LiOH}, \\
2 \mathrm{Li}+2 \mathrm{H}_{2} \mathrm{O}=2 \mathrm{LiOH}+\mathrm{H}_{2},
\end{gathered}
$$

$$
\begin{gathered}
4 \mathrm{~B}+3 \mathrm{O}_{2}=2 \mathrm{~B}_{2} \mathrm{O}_{3}, \\
\mathrm{~B}_{2} \mathrm{O}_{3}+3 \mathrm{H}_{2} \mathrm{O}=2 \mathrm{H}_{3} \mathrm{BO}_{3} .
\end{gathered}
$$

В реакции окисления $\mathrm{Fe}(1)$ и гидролиза $\mathrm{Li}$ (2) выделяется $\mathrm{H}_{2}$, избыток которого в рабочей атмосфере наблюдался в эксперименте (рис. 8). Кроме того, надо обратить внимание на то, что при распылении сплава $\mathrm{Co}_{40} \mathrm{Fe}_{40} \mathrm{~B}_{20}$ выделение $\mathrm{H}_{2}$ прекращается сразу после выключения источников распыления, а в случае $\mathrm{LiNbO}_{3}$ водород в значительных количествах выделяется при прекращении синтеза пленки. Действительно, реакция гидролиза $\mathrm{Li}$ (2) протекает во влажном воздухе при комнатной температуре вследствие высокой химической активности элемента.

Таким образом, существенный сдвиг порога протекания при получении композитов с добавлением реактивных газов и паров воды в сторону больших значений концентрации металлической фазы свидетельствует о значительном увеличении объемной концентрации диэлектрической фазы. Следовательно, в состав диэлектрической фазы входят окислы металлов и ее можно

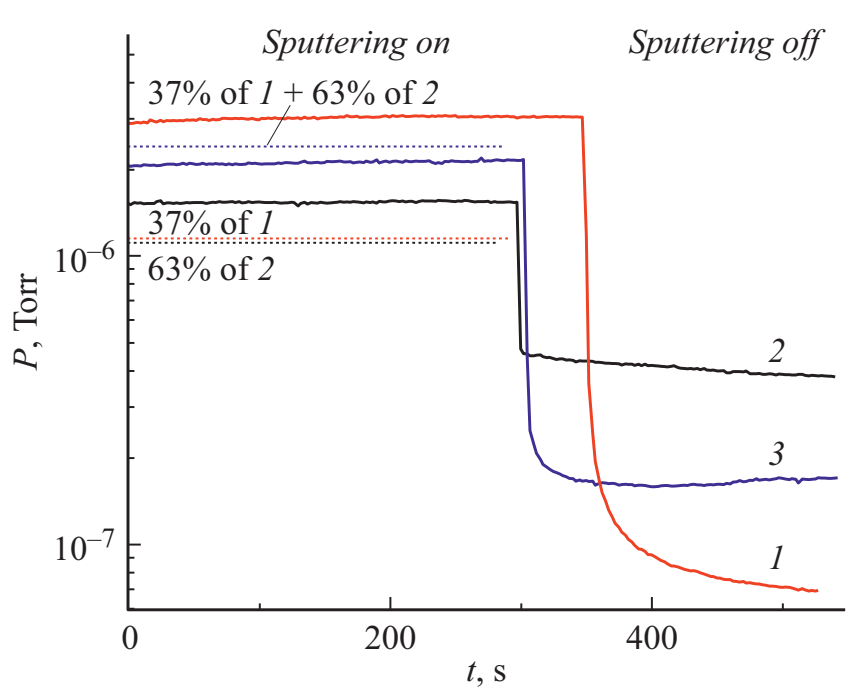

Рис. 8. Временные зависимости давления $\mathrm{H}_{2}$ в вакуумной камере при распылении сплава $\mathrm{Co}_{40} \mathrm{Fe}_{40} \mathrm{~B}_{20}$ (кривая 1), соединения $\mathrm{LiNbO}_{3}$ (кривая 2) и составной мишени $\mathrm{Co}_{40} \mathrm{Fe}_{40} \mathrm{~B}_{20} \mathrm{c}$ навесками из $\mathrm{LiNbO}_{3}$ (кривая 3) в атмосфере $\mathrm{Ar}$ с добавлением паров $\mathrm{H}_{2} \mathrm{O}(3.2 \%)$. 
интерпретировать как сложный оксид $\mathrm{LiNbCoFeBO}_{n}$. К сожалению, современные методы исследований не позволяют точно интерпретировать состав объектов масштаба единицы нанометра. По этой причине представление композитов формулой $\left(\mathrm{Co}_{40} \mathrm{Fe}_{40} \mathrm{~B}_{20}\right)_{x}\left(\mathrm{LiNbO}_{3}\right)_{100-x}$ является общепринятым и скорее характеризует состав мишени, из которой проводилось распыление, чем реальный объект исследования. Из представленных результатов видно, что скорость окисления металлической фазы при осаждении гетерогенной пленки выше в среде, содержащей $\mathrm{O}_{2}$, чем в среде с парами $\mathrm{H}_{2} \mathrm{O}$. Можно предположить, что наличие высокой концентрации $\mathrm{H}_{2}$ (рис. 7,8) при распылении в среде с парами $\mathrm{H}_{2} \mathrm{O}$ способствует частичному восстановлению образующихся оксидов металлов из сплава $\mathrm{Co}_{40} \mathrm{Fe}_{40} \mathrm{~B}_{20}$. Этот механизм, возможно, объясняет тенденцию выхода в насыщение зависимости порога протекания от парциального давления $\mathrm{H}_{2} \mathrm{O}$ (рис. 4). Возможное наличие соединения в диэлектрической фазе $\mathrm{LiOH}$ не оказало существенного влияния на исследуемые в настоящей работе электрические параметры композитов.

В заключение работы отметим также, что анизотропия формы гранул, индуцированная ростом, оказывает влияние не только на электрические свойства, но и на анизотропию магнитных свойств нанокомпозитов [22].

\section{Заключение}

Исследовано влияние добавления молекул кислорода и паров воды в распылительную камеру в процессе осаждения тонкопленочных нанокомпозитов $\left(\mathrm{Co}_{40} \mathrm{Fe}_{40} \mathrm{~B}_{20}\right)_{x}\left(\mathrm{LiNbO}_{3}\right)_{100-x}$ на состав, структуру и электрические свойства гетерогенной системы. Показано, что при ионно-лучевом распылении составной мишени сплава $\mathrm{Co}_{40} \mathrm{Fe}_{40} \mathrm{~B}_{20}$ с навесками соединения $\mathrm{LiNbO}_{3}$ в инертной среде (Ar) диэлектрическая фаза композитов имеет недостаток атомов кислорода и может быть представлена как $\mathrm{LiNbO}_{n}$, где $n<3$. При добавлении молекул кислорода происходит частичное окисление металлической фазы композитов и доокисление соединения $\mathrm{LiNbO}_{n}$. Если в качестве активного газа используются пары воды, то происходит частичное окисление атомов сплава $\mathrm{Co}_{40} \mathrm{Fe}_{40} \mathrm{~B}_{20}$, а литий может образовывать соединение $\mathrm{LiOH}$, входящее в состав диэлектрической фазы композита.

Выявлено значительное повышение удельного электрического сопротивления нанокомпозитов $\left(\mathrm{Co}_{40} \mathrm{Fe}_{40} \mathrm{~B}_{20}\right)_{x}\left(\mathrm{LiNbO}_{3}\right)_{100-x}$ с увеличением парциального давления реактивных газов. Скорость окисления металлической фазы при осаждении гетерогенной пленки в среде, содержащей $\mathrm{O}_{2}$, выше, чем в среде, содержащей пары $\mathrm{H}_{2} \mathrm{O}$. Существенный сдвиг порога протекания при получении композитов с добавлением реактивных газов в сторону больших значений металлической фазы свидетельствует о значительном увеличении объемной концентрации диэлектрической фазы. Обнаружено, что порог протекания при измерении в перпендикулярной к плоскости пленки геометрии соответствует существенно меньшей концентрации атомов сплава $\mathrm{Co}_{40} \mathrm{Fe}_{40} \mathrm{~B}_{20}$, чем в случае измерений в плоскости пленки. Это различие связано с размерным эффектом из-за существенного различия расстояний между омическими контактами при данных методах измерения электрических характеристик, эффектами подавления кулоновской блокады сильным поперечным электрическим полем и анизотропией формы гранул, вытянутых в направлении роста пленки.

\section{Благодарности}

При изучении структуры нанокомпозита использовалось оборудование ресурсного центра электрофизических методов (НИЦ „Курчатовский институт“б).

\section{Финансирование работы}

Работа выполнена при финансовой поддержке Российского фонда фундаментальных исследований (грант № 19-29-03022 мк).

\section{Конфликт интересов}

Авторы заявляют, что у них нет конфликта интересов.

\section{Список литературы}

[1] В.В. Рыльков, А.В. Емельянов, С.Н. Николаев, К.Э. Никируй, А.В. Ситников, Е.А. Фадеев, В.А. Демин, А.Б. Грановский. ЖЭТФ, $158(7), \quad 164$ (2020). DOI: $\quad 10.31857 /$ S0044451020070159 [V.V. Rylkov, A.V. Emelyanov, S.N. Nikolaev, K.E. Nikiruy, A.V. Sitnikov, E.A. Fadeev, V.A. Demin, A.B. Granovsky. JETP, 131 (1), 160 (2020) DOI: 10.1134/S1063776120070109]

[2] S.V. Komogortsev, L.A. Chekanova, I.V. Nemtsev, G.Y. Yurkin, R.S. Iskhakov, G.S. Krainova, N.V. Il'in, V.S. Plotnikov, D.A. Yatmanov. Inorganic Mater: Appl. Res., 11(1), 177 (2020). DOI: 10.1134/S2075113320010219

[3] A.N. Yurasov, M.M. Yashin, D.V. Semenova, K.B. Mirzokulov, E.A. Ganshina. Bull. Russ. Academ. Sci.: Phys., 83 (7), 884 (2019). DOI: 10.3103/S1062873819070438

[4] Ю.Е. Калинин, А.В. Ситников, О.В. Стогней. Междунар. научный журн. Альтернативная энергетика и экология, 54, 9 (2007).

[5] I.V. Bykov, E.A. Gan'shina, A.B. Granovskii V.S. Gushchin. Phys. Solid State, 42 (3), 498 (2000).

DOI: $10.1134 / 1.1131238$

[6] С.А. Гриднев, Ю.Е. Калинин, А.В. Ситников, О.В. Стогней. Нелинейные явления в нано- и микрогетерогенных системах (БИНОМ. Лаборатория знаний, М., 2012) 
[7] А.Н. Мацукатова, А.В. Емельянов, А.А. Миннеханов, Д.А. Сахарутов, А.Ю. Вдовиченко, Р.А. Камышинский, В.А. Демин, В.В. Рыльков, П.А. Форш, С.Н. Чвалун, П.К. Кашкаров. Письма в ЖТФ, $46(2), \quad 25$ (2020). DOI: $\quad$ 10.21883/PJTF.2020.02.48948.18064 [A.N. Matsukatova, A.V. Emelyanov, A.A. Minnekhanov, D.A. Sakharutov, A.Yu. Vdovichenko, R.A. Kamyshinskii, V.A. Demin, V.V. Rylkov, P.A. Forsh, S.N. Chvalun, P.K. Kashkarov. Tech. Phys. Lett., 46 (1), 73 (2020). DOI: $10.1134 / \mathrm{S} 1063785020010277]$

[8] А.В. Архипов, Г.В. Ненашев, А.Н. Алешин. ФТТ, 63 (4), 559 (2021). DOI: 10.21883/FTT.2021.04.50725.263

[9] W. Li, X. Liu, Y. Wang, Z. Dai, W. Wu, L. Cheng, Y. Zhang, Q. Liu, X. Xiao, C. Jiang. Appl. Phys. Lett., 108, 153501 (2016). DOI: $10.1063 / 1.4945982$

[10] Е.В. Окулич, В.И. Окулич, Д.И. Тетельбаум. Письма в ЖТФ, $46(1), \quad 24 \quad$ (2020). DOI: 10.21883/PJTF.2020.01.48859.18003 [E.V. Okulich, V.I. Okulich, D.I. Tetel'baum. Tech. Phys. Lett., 46 (1), 19 (2020). DOI: 10.1134/S1063785020010083]

[11] A. Mehonic, A.L. Shluger, D. Gao, I. Valov, E. Miranda, D. Ielmini, A. Bricalli, E. Ambrosi, C. Li, J.J. Yang, Q. Xia, A.J. Kenyon. Adv. Mater., 1801187, 1 (2018). DOI: $10.1002 /$ adma.201801187

[12] Ю.Е. Калинин, А.В. Ситников, О.В. Стогней. Вестник Воронежского гос. тех. ун-та, 3 (11), 6 (2007).

[13] В.В. Рыльков, С.Н. Николаев, В.А. Демин, А.В. Емельянов, А.В. Ситников, К.Э. Никируй, В.А. Леванов, М.Ю. Пресняков, А.Н. Талденков, А.Л. Васильев, К.Ю. Черноглазов, А.С. Веденеев, Ю.Е. Калинин, А.Б. Грановский, В.В. Тугушев, А.С. Бугаев. ЖЭТФ, 153 (3), 424 (2018). DOI: 10.7868/S0044451018030094 [V.V. Rylkov, S.N. Nikolaev, V.A. Demin; A.V. Emelyanov, A.V. Sitnikov, K.E. Nikiruy, V.A. Levanov, M.Yu. Presnyakov, A.N. Taldenkov, A.L. Vasiliev, K.Yu. Chernoglazov, A.S. Vedeneev, Yu.E. Kalinin, A.B. Granovsky, V.V. Tugushev, A.S. Bugaev. J. Experiment. Theor. Phys., 126 (3), 353 (2018). DOI: $10.1134 / \mathrm{S} 1063776118020152]$

[14] Ю.Ю. Тарасевич. Перколяция: теория, приложения, алгоритмы, учеб. пособие (УРСС, М., 2002)

[15] Ф.Д. Помогайло, А.С. Розенберг, И.Б. Уфлянд. Наночастицы металлов в полимерах (Наука, М., 2000)

[16] Н.Н. Трофимов, М.З. Канович, В.И. Натрусов, А.Т. Пономаренко, В.Г. Шевченко, В.И. Соколов, В.Д. СимоновЕмельянов. Физика композиционных материалов, в 2 т. (Мир, М., 2005), т. 2, с. 344.

[17] И.А. Чмутин, С.В. Летягин, В.Г. Шевченко, А.Т. Пономаренко. Высокомолекулярные соединения, 36, 699 (1994).

[18] Б.И. Шкловский, А.Л. Эфрос. Электронные свойства легированных полупроводников (Наука, М., 1979)

[19] А.В. Ситников, И.В. Бабкина, Ю.Е. Калинин, А.Е. Никонов, М.Н. Копытин, К.Э. Никируй, А.И. Ильясов, К.Ю. Черноглазов, С.Н. Николаев, А.Л. Васильев, А.В. Емельянов, В.А. Демин, В.В. Рыльков. Наноиндустрия, 13 (S4), 570 (2020). DOI: $10.22184 / 1993-8578.2020 .13 .4 s .570 .571$

[20] O.G. Udalov, N.M. Chtchelkatchev, A. Glatz, I.S. Beloborodov. Phys. Rev. B, 89, 054203 (2014).

DOI: 10.1103/PhysRevB.89.054203
[21] Л.В. Гурвич, Г.В. Карачевцев, В.Н. Кондратьев, Ю.А. Лебедев, В.А. Медведев, В.К. Потапов, Ю.С. Ходеев. Энергия разрыва химических связей. Потенциал ионизации и сродство к электрону (Наука, М., 1974)

[22] J.V. Kasiuk, J.A. Fedotova, J. Przewoznik, J. Zukrowski, M. Sikora, Cz. Kapusta, A. Grce, M. Milosavljevic. J. Appl. Phys., 116, 044301 (2014). DOI: 10.1063/1.4891016 